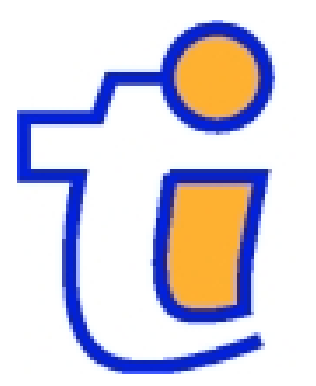

TI 2001-034/1

Tinbergen Institute Discussion Paper

Complete and I ncomplete Markets with Short-Sale Constraints

Eduardo L. Giménez 
Tinbergen Institute

The Tinbergen Institute is the institute for economic research of the Erasmus Universiteit Rotterdam, Universiteit van Amsterdam and

Vrije Universiteit Amsterdam.

Tinbergen I nstitute Amsterdam

Keizersgracht 482

1017 EG Amsterdam

The Netherlands

Tel.: +31.(0)20.5513500

Fax: $\quad+31 .(0) 20.5513555$

Tinbergen Institute Rotterdam

Burg. Oudlaan 50

3062 PA Rotterdam

The Netherlands

Tel.: $\quad+31 .(0) 10.4088900$

Fax: $\quad+31 .(0) 10.4089031$

Most TI discussion papers can be downloaded at

http://www.tinbergen.nl 


\title{
Complete and Incomplete Markets with Short-Sale Constraints
}

\author{
Eduardo L. Giménez * \\ Universidade de Vigo \\ E36200 Vigo (Galiza) Spain \\ e-mail: <egimenez@setei.uvigo.es>
}

March 14, 2001

\begin{abstract}
This paper argues that the introduction of a short-sale constraint in the ArrowRadner framework invalidates standard definitions of complete and incomplete markets. In this constrained set-up, two threshold values with familiar properties arise. The case of a zero short-sale bound set on some security fulfills the standard definition of "incomplete" financial markets. Beyond a particular level of the short-sale bound financial markets are "complete", since the short-sale constraint is not active. For intermediate bounds the distinction between complete and incomplete financial markets is blurred. Although some technical definitions hold, agents can not fully transfer wealth among states. These intermediate cases, called "technically incomplete markets", exhibit interesting welfare properties. For instance, the resulting equilibrium allocations may not be Pareto dominated by those of the non-restricted complete markets equilibrium.

Keywords: Complete Markets, Incomplete Markets, Technically Incomplete Markets, Short-Sale Constraint.
\end{abstract}

JEL: D52, D61, G12

*The discussions with Narayana Kocherlakota and Edward Green have inspired this work. I thank David Cass for useful insights. 


\section{1.- Introduction}

In the standard Arrow-Debreu framework there are several equivalent characterizations of complete and incomplete financial markets. First, financial markets are complete whenever the matrix of dividends has full rank; else, markets are incomplete. ${ }^{1}$ Second, the standard economic intuition is that financial markets are complete if agents can transfer as much wealth as desired among different states. In contrast, when financial markets are incomplete individuals can only make wealth transfers over a certain subspace. Third, financial markets are said to be complete if a unique state price process verifies the asset pricing equation. Fourth, financial markets are complete whenever any new security introduced into the economy can be uniquely priced; else, for the latter two cases, financial markets are incomplete.

This paper illustrates that in the presence of a short-sale constraint on a security, the distinction between complete and incomplete financial markets becomes blurred. In such restricted set-up financial markets lie at an intermediate case between complete and incomplete markets, referred to as "technically incomplete markets" by Santos and Woodford $(1992,1996)$. The present work clarifies previous arguments discussed by Santos and Woodford.

Regarding efficiency, it is known that incomplete markets generate allocations that are Pareto dominated by those found in complete markets, because agents are unable to smooth their consumption patterns. ${ }^{2}$ The reason for this inefficiency stems from the existing scarcity of securities. An example will be presented in which the existence of a short-sale constraint on an asset may have perverse welfare effects, although the number of non-redundant securities is equal to the number of successor states.

The example consists of a stochastic two-period Arrow-Radner economy. There are two agents with identical quasilinear preferences but heterogeneous in endowments. Two inside Arrow securities are traded in the first period. Initially, an equilibrium allocation and corresponding prices are found for the non-constrained case. The state price process is unique and thus any new security introduced into the economy is uniquely priced. Then a shortsale constraint on one security is introduced. Two threshold values with familiar properties arise. On the one hand, in the case of a zero-bound constraint, the standard definition of "incomplete markets" is satisfied. The restricted security is not traded because of the inside feature of the assets. On the other hand, there exists a value of the short-sale bound for which the restriction is not binding for any agent. The level of this threshold value depends on the primitives of the economy, i.e., the discount factor, [[and]] the agent's preferences and endowment distribution. Beyond this threshold value, the standard definition of "complete markets" is verified in this setting, since the constraint is not active. In contrast, when the short-sale bound lies between zero and this threshold, the short-sale constraint is binding and financial markets fall into a category of markets called "technically incomplete markets".

\footnotetext{
${ }^{1}$ To illustrate, consider an economy with 2 periods $t=0,1$. There is a single node at period $t=0$ and there are $S=\left\{s_{1}, s_{2}, \ldots, s_{S}\right\}$ states at period $t=1$. It is said that financial markets are complete at period $t=0$ if the number of non-redundant securities (defined by $(q, D)$, where $q$ is a vector of security prices and $D$ a matrix of dividends) traded at this period is equal to the number of immediate successor states; i.e., $\operatorname{rank}(D)=S$. If $\operatorname{rank}(D)<S$, financial markets are incomplete.

${ }^{2}$ See Hart (1975), Wilson (1987) and LeRoy and Werner (2001, Chap.16).
} 
A primary implication of this analysis is that when the space of available portfolios is restricted, the technical definitions of complete and incomplete markets are no longer valid. In the presence of a financial constraint, the standard technical definitions of complete markets and the underlying economic intuition fail. For example, an agent may not be able to smooth consumption as desired even though the number of non-redundant securities is equal to the number of immediate successor states; i.e., when the matrix of dividends has full rank. Further, several state-price processes verify the same asset pricing equation because the existence of a short-sale constraint introduces an additional shadow price in the asset pricing equation. And, any new security introduced into the economy may not be uniquely priced.

In addition, exogenous changes in the borrowing restriction may lead to interesting welfare features. Equilibrium welfare properties will be analyzed for the intermediate region that ranges from "standard incomplete markets" to "standard complete markets", in which the short-sale constraint is active. Under incomplete markets, both agents become worse off. Relaxing the short-sale bound makes both agents better off. For any of these short-sale bounds the unconstrained agent's welfare is always below his welfare resulting from his nonrestricted complete markets allocations. However, from a particular value of the short-sale bound on, the restricted agent's welfare is higher than the resulting welfare obtained when the short-sale constraint is not active. Thus, one can find a short-sale bound for which the restricted agent achieves maximum welfare. Beyond this point, her welfare decreases, although it remains above the level of the non-restricted complete markets. In summary, when financial markets are "technically incomplete", i.e., when the restriction is binding, some equilibrium allocations may not be Pareto dominated by those of the non-restricted complete markets equilibrium. The reason is that the existence of the restriction increases the equilibrium prices of the restricted security, even though the agents are price takers for any given short-sale bound. Hence, the restricted agent ought to borrow less wealth but more cheaply.

Let us conclude with two further comments. First, in the example presented below agents could manipulate prices. An agent could understand that she may improve her welfare if she restrained herself from trading on some security held in short position, i.e., in negative holdings. Thus, the example shows that the equilibrium may be agent-manipulated by increasing the equilibrium price of the self-restricted security. Second, this result may suggest that in the real world some (restricted) financial markets are not open (or deregulated) because they may be subject to lobbying pressures from the part of those agents who may lose welfare -or profits- with higher efficiency in the whole economy.

In the next section, the same example with and without short-sale constraint is presented. Then, a detailed study on completeness and incompleteness of the financial markets is conducted. Section 3 deals with a welfare analysis of equilibria under different short-sale bounds. Section 4 concludes. 


\section{2.- "Complete Markets" and "Incomplete Markets" with a short- sale constraint}

For a sequential competitive market economy it is said that financial markets are complete if the following equivalent criteria -technically and intuitively- are fulfilled: [1] The rank of the matrix of dividends, which coincides with the number of non-redundant securities, is equal to the number of successor states $;^{3}[2]$ agents are unrestricted in their wealth transfers across states; ${ }^{4}$ [3] a unique state price process verifies the asset pricing-equation; ${ }^{5}$ and [4] the introduction of any new security into the economy can be priced in a unique way. ${ }^{6}$

An example follows to illustrate that these criteria may not apply in the presence of a constraint that precludes some kinds of security transactions.

Non-restricted example. Consider a two-period economy, with two states $\bar{s}$ and $\underline{s}$ at the second period. The state at period $t=0$ is denoted by $s_{0}$. The economy is populated by two agents represented by $h=P, R$. Their endowments are $\omega^{h}=\left(\omega_{0}^{h}, \bar{\omega}^{h}, \underline{\omega}^{h}\right)$. Preferences are defined by a quasilinear utility function $U\left(c_{0}^{h}, \bar{c}^{h}, \underline{c}^{h}\right)=c_{0}^{h}+\beta \operatorname{Ln} \bar{c}^{h}+\beta \operatorname{Ln} \underline{c}^{h}$ with $\beta \in(0,1)$. Suppose that there exist two Arrow securities: $\bar{z}$ defined by $(\bar{q},(1,0))$, and $\underline{z}$ defined by $(\underline{q},(0,1))$. Here financial markets are (obviously) complete at $t=0$. Equilibrium allocations for any agent $h$, security prices, and state price process $\left(a_{0}, \bar{a}, \underline{a}\right)$, given the normalization $a_{0}=1$, are as follows

\begin{tabular}{||c||c|c|c||c||c|c||}
\hline \hline$s_{0}$ & $\bar{s}$ & $\underline{s}$ & & - & - \\
\hline \hline \multirow{2}{*}{$c^{h}$} & $\omega_{0}^{h}+2 \beta\left(\frac{\bar{\omega}^{h}}{\bar{\omega}}+\frac{\underline{\omega}^{h}}{\underline{\omega}}-1\right)$ & $\frac{\bar{\omega}}{2}$ & $\frac{\omega}{2}$ & $z^{h}$ & $\frac{\bar{\omega}}{2}-\bar{\omega}^{h}$ & $\frac{\underline{\omega}}{2}-\underline{\omega}^{h}$ \\
\hline$a$ & 1 & $\frac{2 \beta}{\bar{\omega}}$ & $\frac{2 \beta}{\underline{\omega}}$ & $q$ & $\frac{2 \beta}{\bar{\omega}}$ & $\frac{2 \beta}{\underline{\omega}}$ \\
\hline \hline
\end{tabular}

where $\bar{\omega}$ and $\underline{\omega}$ are the aggregate endowment in the state $\bar{s}$ and $\underline{s}$, respectively. In this set-up agents can freely transfer wealth across states using the available financial structure. The resultant utility level achieved by each agent is then

$$
U^{h}=\omega_{0}^{h}+2 \beta\left(\frac{\bar{\omega}^{h}}{\bar{\omega}}+\frac{\underline{\omega}^{h}}{\underline{\omega}}-1\right)+\beta\left(\operatorname{Ln} \frac{\bar{\omega}}{2}+\operatorname{Ln} \frac{\underline{\omega}}{2}\right) .
$$

\footnotetext{
${ }^{3}$ See Hakansson (1987). That is, $\operatorname{rank}(D)=N=S$, where $N$ is the number of non-redundant securities and $S$ the number of successor states. Duffie $(1996$, p.8) offers an analogous definition: "With $\operatorname{span}(D) \equiv$ $\left\{D^{\prime} z: z \in \mathcal{R}^{N}\right\}$ denoting the set of possible portfolio payoffs, markets are complete if $\operatorname{span}(D)=\mathcal{R}^{S}$, and are otherwise incomplete."

${ }^{4}$ Mas-Collel et al (1995) p.704. That is, agents can freely transfer wealth across states.

${ }^{5}$ For example, see LeRoy and Werner (2001, Sec. 2.5 and Sec. 5.5) or Duffie (1996, ex.1.14).

${ }^{6}$ See LeRoy and Werner (2001, Sec. 2.5 and Theorem 5.5.1). This criterium and the previous one are equivalent, since both are a direct consequence of the uniqueness of the pay-off pricing functional in complete markets.
} 
In this non-restricted case all criteria for financial markets to be complete are equivalent: $\operatorname{rank}(D)=2$; agents can freely transfer wealth as desired; if any new security is introduced, e.g., $(\hat{q},(\bar{d}, \underline{d}))$, it can be priced in only one way, that is $\hat{q}=\bar{d} \bar{q}+\underline{d} \underline{q}$. Finally, since the state price process for any security $\left(q_{j},\left(\bar{d}_{j}, \underline{d}_{j}\right)\right)$ is

$$
a_{0} q_{j}=\bar{a} \bar{d}_{j}+\underline{a}_{d_{j}}
$$

there is a unique state price process up to normalization of $a_{0}=1$; i.e., $a=\left(a_{0}, \bar{a}, \underline{a}\right)=$ $\left(1, \frac{2 \beta}{\bar{\omega}}, \frac{2 \beta}{\underline{\omega}}\right)$.

Restricted example. Now suppose that in the previous economy one of the securities is restricted by a short-sale constraint, e.g., $\bar{z}^{h}>-A$ for any $h$, where $A$ is a non-negative number. In this case agent $h$ 's problem is

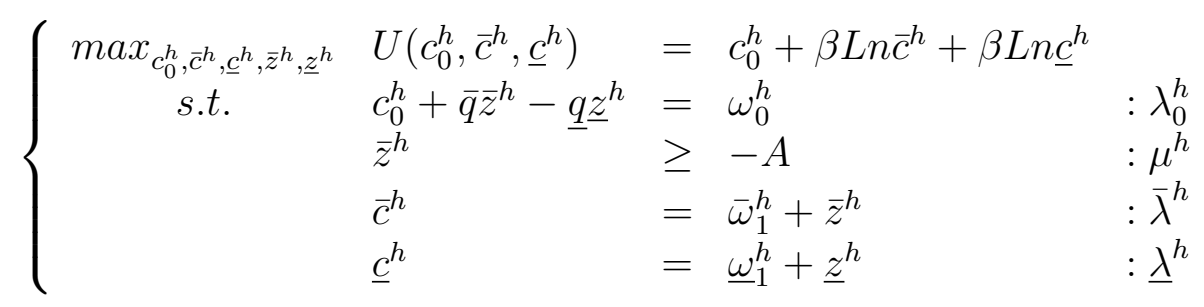

where $\lambda$ is the multiplier of the budget constraint and $\mu$ is the multiplier of the shortsale constraint. Let us assume that agent $h=P$ is the one who needs to sell the restricted security ${ }^{7} \bar{z}$ (i.e., to hold security $\bar{z}$ in short position). Then $\mu^{P} \geq 0$ since $\bar{z}^{P}=-A$. Therefore the other agent $h=R$ will buy the security. That is, $\mu^{R}=0$ because $\bar{z}^{R}>-A$. For this restricted set-up equilibrium allocations and security prices can be expressed as

\begin{tabular}{||c||c|c|c||c||c|c||}
\hline \hline & $s_{0}$ & $\bar{s}$ & $\underline{s}$ & & $\cdot$ & - \\
\hline \hline$c^{P}$ & $\omega_{0}^{P}+\beta\left(+\frac{A}{\bar{\omega}^{R}+A}+\frac{2 \omega^{P}}{\underline{\omega}}-1\right)$ & $\bar{\omega}^{P}-A$ & $\frac{\omega}{2}$ & $z^{P}$ & $-A$ & $\frac{\omega}{2}-\underline{\omega}^{P}$ \\
$c^{R}$ & $\omega_{0}^{R}+\beta\left(-\frac{A}{\bar{\omega}^{R}+A}+\frac{2 \underline{\omega}^{R}}{\underline{\omega}}-1\right)$ & $\bar{\omega}^{R}+A$ & $\frac{\underline{\omega}}{2}$ & $z^{R}$ & $A$ & $\frac{\underline{\omega}}{2}-\underline{\omega}^{R}$ \\
\hline$\lambda^{P}$ & 1 & $\frac{2 \beta}{\bar{\omega}}$ & $\frac{2 \beta}{\underline{\omega}}$ & $q$ & $\frac{\beta}{\bar{\omega}^{R}+A}$ & $\frac{2 \beta}{\underline{\omega}}$ \\
$\mu^{P}$ & $\beta \frac{\overline{\bar{\omega}}^{P}-\bar{\omega}^{R}-2 A}{\left.\left(\bar{\omega}^{R}+A\right) \bar{\omega}^{P}-A\right)}$ & - & - & & & \\
\hline$\lambda^{R}$ & 1 & $\frac{\beta}{\bar{\omega}^{R}+A}$ & $\frac{2 \beta}{\underline{\omega}}$ & & & \\
$\mu^{R}$ & 0 & - & - & & & \\
\hline \hline
\end{tabular}

Note that agents cannot transfer as much wealth as desired through securities. Welfare achieved is as follows:

$$
\begin{aligned}
U^{P} & =\omega_{0}^{P}+\beta\left(\frac{A}{\bar{\omega}^{R}+A}+\frac{2 \underline{\omega}^{P}}{\underline{\omega}}-1\right)+\beta\left[\operatorname{Ln}\left(\bar{\omega}^{P}-A\right)+\operatorname{Ln} \frac{\underline{\omega}}{2}\right] \\
U^{R} & =\omega_{0}^{R}+\beta\left(-\frac{A}{\bar{\omega}^{R}+A}+\frac{2 \underline{\omega}^{R}}{\underline{\omega}}-1\right)+\left[\operatorname{Ln}\left(\bar{\omega}^{R}+A\right)+\operatorname{Ln} \frac{\underline{\omega}}{2}\right]
\end{aligned}
$$

\footnotetext{
${ }^{7}$ This will happen whenever the prevailing condition is the following: $\bar{\omega}^{R}+A<\frac{\bar{\omega}}{2}$.
} 
The key question here is the following: are financial markets complete at $t=0$ ? In line with the previous criteria, the answer would be in the affirmative since $\operatorname{rank}(D)=2$, which equals the number of successor states. ${ }^{8}$ Hence, a unique state price process satisfing the asset pricing equation $a_{0} q_{j}=\bar{a} \bar{d}_{j}+\underline{a}_{\underline{d}} \underline{j}_{j}$ should exist. This means that "only the rich agent matters", and only his first order conditions has to be taken into account. The poor agent experiences a short-sale restriction, so her first order conditions involve certain side-constraints. ${ }^{9}$ Thus, in equilibrium

$$
\begin{aligned}
& \bar{q}=\frac{\bar{\lambda}^{R}}{\lambda_{0}^{R}} \times 1+\frac{\underline{\lambda}^{R}}{\lambda_{0}^{R}} \times 0=\frac{\bar{\lambda}^{R}}{\lambda_{0}^{R}}=\frac{\frac{\partial U^{R}}{\partial \bar{c}^{R}}}{\frac{\partial U^{R}}{\partial c_{0}}}=\frac{\beta}{\bar{\omega}^{R}+A} \\
& \underline{q}=\frac{\bar{\lambda}^{R}}{\lambda_{0}^{R}} \times 0+\frac{\underline{\lambda}^{R}}{\lambda_{0}^{R}} \times 1=\frac{\bar{\lambda}^{R}}{\lambda_{0}^{R}}=\frac{\frac{\partial U^{R}}{\partial \underline{c}^{R}}}{\frac{\partial U^{R}}{\partial c_{0}}}=\frac{2 \beta}{\underline{\omega}}
\end{aligned}
$$

Therefore, making $a_{0}=1$, there is a unique state price process , i.e., $a=\left(a_{0}, \bar{a}, \underline{a}\right)=$ $\left(1, \frac{\beta}{\bar{\omega}^{R}+A}, \frac{2 \beta}{\underline{\omega}}\right)$. It then seems that financial markets are complete.

On the other hand, can agents transfer all the wealth they desire between periods? No. In such a case, it may be suggested that there exist incomplete financial markets (or perhaps, it would be better to call them "technically incomplete" markets, as do Santos and Woodford, 1992, 1996). In this scenario, several state-price processes verify the asset pricing equation should exist. Which one is then the right asset pricing equation? Following of Svensson (1985), Santos and Woodford (1992, 1996), and Giménez $(1996,1998)$ intangible returns has to be taken into account when a financial restriction is introduced in the standard ArrowRadner economy. Then, the asset pricing formula is,

$$
a_{0} q_{j}=\bar{a} \bar{d}_{j}+\underline{a d}_{j}+r_{0}
$$

where $r_{0}$ is a shadow price which results from the existence of the short-sale restriction. Both agents' first order conditions are taken into account, since there are several equilibrium state-price processes. ${ }^{10}$ For the rich agent

$$
\begin{aligned}
\bar{q} & =\frac{\bar{\lambda}^{R}}{\lambda_{0}^{R}} \times 1+\frac{\underline{\lambda}^{R}}{\lambda_{0}^{R}} \times 0+\frac{\mu^{R}}{\lambda_{0}^{R}}=\frac{\bar{\lambda}^{R}}{\lambda_{0}^{R}}+\frac{\mu^{R}}{\lambda_{0}^{R}} \\
\underline{q} & =\frac{\bar{\lambda}^{R}}{\lambda_{0}^{R}} \times 0+\frac{\lambda^{R}}{\lambda_{0}^{R}} \times 1=\frac{\underline{\lambda}^{R}}{\lambda_{0}^{R}}
\end{aligned}
$$

\footnotetext{
${ }^{8}$ Observe, however, that in the presence of a constraint on security trading the definition of complete markets in Duffie (1996) is not equivalent, since $\operatorname{span} D \subset \mathcal{R}^{S}$.

${ }^{9}$ Agent $h$ 's first order conditions for securities are the following

$$
\begin{aligned}
\lambda_{0}^{h} \bar{q} & =\bar{\lambda}^{h}+\mu^{h} \\
\lambda_{0}^{h} \underline{q} & =\underline{\lambda}^{h} \\
\mu^{h}\left[-A-\bar{z}^{h}\right] & =0
\end{aligned}
$$

${ }^{10}$ Realize now that, in equilibrium, agents' first order conditions could be reinterpreted as the asset pricing equations.
} 
Therefore, after the normalization $a_{0}=1$, one generalized state price process is $(a, r)=$ $\left(a_{0}, \bar{a}, \underline{a}, r_{0}\right)=\left(1, \frac{\beta}{\bar{\omega}^{R}+A}, \frac{2 \beta}{\underline{\omega}}, 0\right)$.

Regarding the poor agent

$$
\begin{aligned}
\bar{q} & =\frac{\bar{\lambda}^{P}}{\lambda_{0}^{P}} \times 1+\frac{\lambda^{P}}{\lambda_{0}^{P}} \times 0+\frac{\mu^{P}}{\lambda_{0}^{P}}=\frac{\bar{\lambda}^{P}}{\lambda_{0}^{P}}+\frac{\mu^{P}}{\lambda_{0}^{P}} \\
\underline{q} & =\frac{\bar{\lambda}^{P}}{\lambda_{0}^{P}} \times 0+\frac{\lambda^{P}}{\lambda_{0}^{P}} \times 1=\frac{\lambda^{P}}{\lambda_{0}^{P}}
\end{aligned}
$$

After the normalization $a_{0}=1$, other generalized state price system is given by $(a, r)=$ $\left(a_{0}, \bar{a}, \underline{a}, r_{0}\right)=\left(1, \frac{2 \beta}{\bar{\omega}}, \frac{2 \beta}{\underline{\omega}}, \beta \frac{\bar{\omega}^{P}-\bar{\omega}^{R}-2 A}{\left(\bar{\omega}^{R}+A\right)\left(\bar{\omega}^{P}-A\right)}\right)$. That is, there exist different multipliers for each agent. These are "personalized multipliers", which are not collinear. Consequently several state price processes are possible, which suggests that financial markets are incomplete.

In addition, if any new security is introduced, e.g., $(\hat{q},(\bar{d}, \underline{d}))$, it can not be priced in a single way. It might be expected that $\hat{q}=\bar{d} \bar{q}+\underline{d q}$. However, if this security is introduced in the maximization problem, its equilibrium price would be $\hat{q}^{*}=2 \beta \frac{\bar{d} \bar{\omega}+\underline{d \omega}}{\bar{\omega} \underline{\omega}}>\hat{q}$, indicating again that financial markets are incomplete.

Finally, in line with Santos and Woodford (1992), one can say that financial markets are complete in an Arrow-Radner economy with short-sale constrains if the matrix of dividends of securities not restricted by the short-sale constraint is equal to the number of successor states; else, financial markets are incomplete. Under this definition, in the above example there exist incomplete markets (or "technically incomplete markets").

\section{3- Comparative statics on welfare}

In this section a welfare analysis under different short-sale bounds is carried out. Two threshold values with familiar properties arise when a short-sale constraint on one security is introduced in the standard Arrow-Radner economy. On the one hand, for the zerobound constraint, the standard definition of "incomplete markets" is satisfied. The restricted security is not traded because of the inside feature of the assets. On the other hand, there exists a value of the short-sale bound beyond which the restriction is not binding for any agent. The level of this threshold value depends on the primitives of the economy, i.e., the discount factor, and the agent's preferences and endowment distribution. ${ }^{11}$ Passing this threshold value, the standard definition of "complete markets" is verified in this setting, since the constraint is not active. In contrast, when the short-sale bound lies between zero and this threshold, the short-sale constraint is binding and financial markets fall into a category of markets called "technically incomplete markets".

\footnotetext{
${ }^{11}$ In the previous example this happens when $A=\frac{1}{2} \bar{\omega}-\bar{\omega}^{R}$.
} 
Thus, for changes in these short-sale bounds one can compute the gains and losses in agents' welfare. In the case of incomplete markets, when the short-sale bound is zero, both agents are worse off than in complete markets. (See Figure 1 for a particular set of parameters.) It is well known that incomplete markets generate allocations that are Pareto inferior to those of the equilibrium allocations in complete markets (see Hart, 1975). Relaxing the short-sale bound makes both agents better off. For any of these limits, the unconstrained agent's welfare is always below his welfare resulting from his non-restricted complete markets allocation. However, from a particular value of the short-sale bound on (see Figure 1), the restricted-agent's welfare is higher than the resulting welfare obtained when the financial constraint is not active. Thus, one can find a short-sale bound for which the restricted-agent achieves maximum welfare. Beyond this point, her welfare decreases, although it remains always above her non-restricted complete markets welfare. In summary, when financial markets are "technically incomplete" some equilibrium allocations may not be Pareto dominated by those of the non-restricted complete markets equilibrium. The reason is that the existence of the restriction increases the equilibrium prices of the restricted security, even though the agents are price takers for any given short-sale bound. Hence, the restricted-agent ought to borrow less wealth from some state, but more cheaply than in the non-restricted case (i.e., the return for debts on restricted security $\bar{R}=\frac{1}{\bar{q}}$ decreases). Consequently, she can consume more at the restricted equilibrium price in period $t=0$ and in state $\bar{s}$ at period $t=1$.

As a final comment, this example presents an economy where agents can manipulate prices. An agent can improve her welfare if she restrained herself from trading the security held in short position, i.e., in negative holdings. This suggests that if some agent understands that she can manipulate equilibrium prices by restricting certain trades, the non-restricted complete markets equilibrium could not be stable.

\section{4.- Concluding Remarks}

A simple example has revealed that the standard definitions of complete and incomplete markets for an Arrow-Radner economy must be adapted if a financial restriction on security trading is active (e.g., a short-sale constraint). A detailed study of different equivalent criteria or definitions of standard complete markets suggests that certain situations constitute an intermediate case between complete markets and incomplete markets, what Santos and Woodford (1996) call "technically incomplete markets". A welfare analysis was also carried out under different short-sale bounds ranging from standard complete markets to standard incomplete markets. The equilibrium allocations under the restricted set-up are not Pareto dominated by the non-restricted equilibrium allocations. The restricted agent may achieve higher welfare than in the non-restricted complete markets set-up because the existence of the restriction increases the equilibrium price of the restricted security. Hence, this agent can transfer less wealth, but in a cheaper way.

As an extension of this work, a case of interest within this set-up is presented in monetary economies within an infinite horizon framework. Since agents cannot hold short positions on 
a security called "money," this asset is restricted by a short-sale constraint. Some authors have argued that, whenever a type of friction (such as a short-sale constraint) is introduced, money represents a claim on an infinite stream of future services represented by its role in the trading process. See Svensson (1985) and Santos and Woodford (1992, 1996) for the cash-in-advance case, Santos and Woodford (1992) for the case of a short-sale constraint, and Giménez $(1996,1998)$ for the case of reserve requirements. In Giménez (2000) the same methodology of these authors (the work rests mainly on Santos and Woodford's 1992 paper) is employed to criticize two examples given by Kocherlakota (1992, example 1) and by Santos and Woodford (1997, example 4.2), where money is presented as pure bubble pricing.

\section{References}

1. Duffie, D.: Dynamic Asset Pricing Theory. Princenton University Press. Princeton. 1996.

2. Giménez-Fernández, E. L.: Valoración de Activos en un Contexto de Restricciones de Reserva. Ph.D.Thesis. Depart. de Economía. Universidad Carlos III de Madrid, 1996.

3. Giménez, E. L.: Rational Asset Pricing with Reserve Requirement Restrictions. Mimeograph, Universidade de Vigo, January 1998.

4. Giménez, E. L.: On the Positive Fundamental Value of Money with Short-Sale Constraints: A comment on two examples. Mimeograph, Universidade de Vigo, May 2000.

5. Hakansson, N. H.: Financial Markets. in John Eatwell, Murray Milgate and Peter Newman (eds.), The New Palgrave. A dictionary of economics. 351-354. MacMillan Press, London, 1987.

6. Hart, O.D.: On the Optimality of Equilibrium when the Market Structure is Incomplete. J. of Econ. Theory 11, 418-443. 1975

7. Kocherlakota, N. R.: Bubbles and Constraints on Debt Accumulation. J. of Econ. Theory 57, 245-256. 1992

8. LeRoy, S. F., Werner J.: Principles of Financial Economics. Cambridge University Press, Edimburg. 2001.

9. Mas-Collel, A.,Whinston, M. D., Green J. R. Microeconomic Theory. Oxford University Press. New York. 1995.

10. Santos, M. S., Woodford, M.: A Value Theory of Money. Mimeograph. Universidad Carlos III de Madrid, November 1992.

11. Santos, M. S., Woodford, M.: A Value Theory of Money. Mimeograph, ITAM, México, D.F., May 1996. 
12. Santos, M. S., Woodford, M.: Rational Speculative Bubbles. Econometrica, 65 n.1, 19-57. 1997.

13. Svensson, L. O.: Money and Asset Prices in a Cash-in-Advance Economy. J. Polit. Econ., 93 n.5, 919-944. 1985.

14. Wilson, C.: Incomplete Markets, in John Eatwell, Murray Milgate and Peter Newman (eds.), The New Palgrave. A dictionary of economics. 759-760. MacMillan Press, London. 1987.

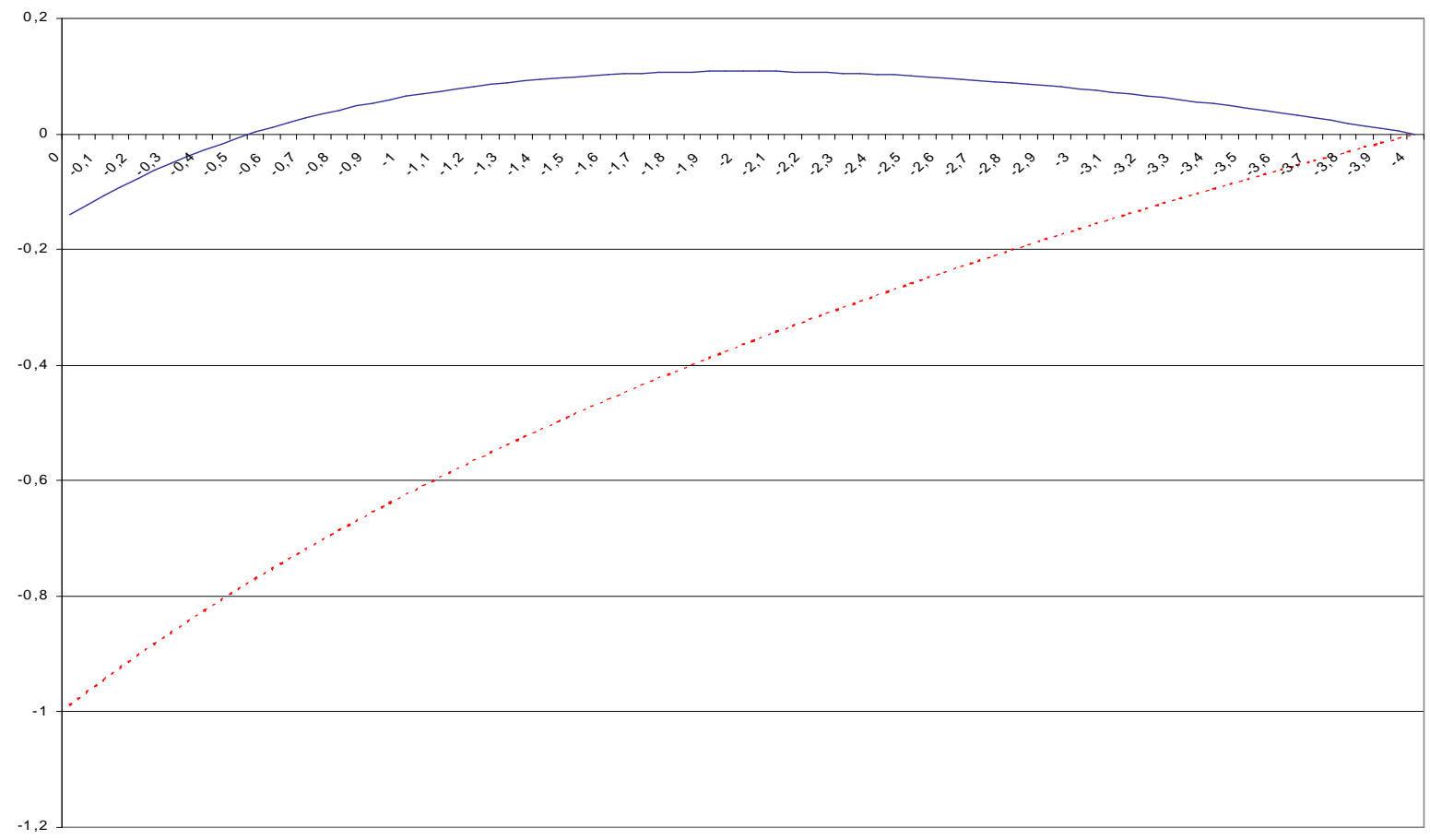

Restricted agent $\cdots \cdots$ Non-Restricted agent

Figure 1. Gains and losses in welfare, under changes on the short-sale bound $A$, with respect to the non-restricted complete markets equilibrium. Case: $\omega^{P}=$ $(10,10,5)$ and $\omega^{R}=(10,2,5)$, and $\beta=0,9$.

Given the restriction $\bar{z}^{h} \geq-A$ : incomplete markets are obtained for $A=0$; complete markets are obtained for $A=4$; the maximum gain of welfare for the restricted agent is obtained for $A=2$. 